\title{
Avaliação da educação superior em Portugal: entrevista com Alberto Amaral
}

\author{
Maria das Graças Gonçalves Vieira Guerra' (D)
}

\section{APRESENTAÇÃO}

Alberto Amaral é doutor em química quântica pela Universidade de Cambridge, Reino Unido. É professor catedrático aposentado do Departamento de Química e Bioquímica (FCUP) e ex-reitor da Universidade do Porto (U.Porto), Portugal, do ano de 1985 a 1998. No período compreendido entre 1998 e 2008, dirigiu o Centro de Investigação de Políticas do Ensino Superior (CIPES), um dos principais núcleos de investigação da educação superior da Europa. Desde 2008, até o presente momento, preside a Agência de Avaliação e Acreditação do Ensino Superior (A3ES), que tem como missão garantir a qualidade da educação superior em Portugal e viabilizar a inserção do país no sistema europeu de garantia da qualidade. É membro do conselho editorial de algumas das mais importantes revistas científicas sobre educação e avaliação, tais como Quality Assurance in Education e Studies in Learning, Evaluation, Innovation and Development e Higher Education Dynamics. É também membro e coordenador científico do conselho consultivo EDULOG, iniciativa da Fundação Belmiro de Azevedo, um think tank com objetivo de contribuir para a construção de um sistema de educação de referência. Foi membro do conselho de reitores das instituições universitárias de Portugal, participou de várias comissões públicas e interministeriais de trabalho e investigações sobre educação superior em diferentes países e foi membro do corpo executivo da European University Association (EUA). Tem diversos títulos e condecorações por suas contribuições para o mundo acadêmico em diferentes países, nomeadamente o Prêmio Centenário do FCUP e a Medalha de Mérito da U.Porto, que recebeu em 2002 (ano de sua aposentadoria), por ter contribuído para o prestígio da Faculdade de Ciências e da U.Porto. Alberto Amaral é editor e coeditor de diversos livros e autor de vários artigos publicados em revistas internacionais sobre os sistemas de educação superior.

Foi responsável por trazer para Portugal um conjunto de novas metodologias de avaliação, primeiramente aplicadas internamente na U.Porto e, depois, generalizadas às universidades públicas, em um processo cuja consequência resultou na criação do Conselho Nacional de Avaliação do Ensino Superior (CNAVES).

'Universidade Federal da Paraíba, João Pessoa, PB, Brasil. 
$\mathrm{O}$ fato de esse diretor, ex-reitor e pesquisador integrar a A3ES como presidente permitiu conhecer o processo avaliativo não só em Portugal, mas também no Espaço Europeu de Ensino Superior (EEES). A entrevista foi realizada no dia 17 de maio de 2018, na unidade do CIPES em Matosinhos, presencialmente, o que permitiu a clarificação de aspectos relacionados com o processo avaliativo.

M.G.G.V.G. - Maria das Graças Gonçalves Vieira Guerra A.M. - Alberto Amaral

M.G.G.V.G. - Vamos dar início à entrevista, aqui no CIPES, com o presidente da A3ES, doutor Alberto Amaral, sobre avaliação. Em primeiro lugar, doutor Alberto Amaral, gostaria que falasse um pouco sobre sua experiência, sobre sua trajetória em relação à questão da avaliação.

A.M. - Eu fui reitor da Universidade do Porto entre 1985 e 1998, portanto 13 anos, e durante esse período as questões da qualidade começaram a aparecer em minha experiência educacional. Por um lado, percebi que era imperativo as universidades portuguesas adotarem esse sistema da qualidade; por outro, porque, à época, eu era também membro da European University Association e vice-presidente da Comissão para a Avaliação, e, nessa condição, participei ativamente em muitas diligências internacionais, comecei a me interessar pela temática. O meu passado é na área da química, doutorei-me em Cambridge, em química quântica, e, quando cheguei ao fim dos 13 anos fora da Universidade do Porto, achei que não deveria voltar para a química quântica, até porque, entretanto, havia colegas mais novos que tinham assumido a direção do centro que eu tinha criado e não fazia sentido nenhum regressar. Por um lado, porque eu me sentia desatualizado e, por outro, os colegas tinham feito um excelente trabalho e, portanto, mereciam ser deixados em paz. A essa altura da minha trajetória profissional, antes de sair da reitoria, decidi criar um centro de investigação em políticas de ensino superior, que é esse que está vigente no país. Ele foi sempre classificado como excelente, e uma das componentes desse centro, que investiga políticas do ensino superior, é incluir, naturalmente, a qualidade. No ano de 2008 , fui convidado, primeiro pelo ministro, depois pelos colaboradores da A3ES, a presidir o conselho de administração da agência, e, portanto, é nesse local que tenho estado até agora. Tenho grande experiência internacional e dediquei atenção a essa temática, que então faz parte da investigação que nós da A3ES fazemos, ou seja, foi um percurso mais ou menos natural. A A3ES tem como missão garantir a qualidade do ensino superior em Portugal, por meio da avaliação e acreditação das instituições de ensino superior e dos seus ciclos de estudos, bem como o desempenho das funções inerentes à inserção de Portugal no sistema europeu de garantia da qualidade do ensino superior. A estrutura orgânica da agência é a seguinte: conselho de curadores; conselho de administração; conselho fiscal; conselho consultivo; conselho de revisão; e conselho científico.

M.G.G.V.G. - O que o levou a integrar a A3ES e a presidir o conselho de administração dessa agência?

A.M. - Primeiro uma conversa com o ministro e, depois, o convite que foi feito pelos colaboradores da A3ES. E, claro, como era uma área pela qual eu tinha interesse, 
naturalmente que decidi assumir a presidência. Além de tudo isso, tinha adquirido um grande interesse na área do ensino superior, na qual criei um centro de investigação, que é o que ainda faço. Só deixei a direção do centro quando vim para a A3ES. Continuo a fazer investigação em paralelo e a própria agência tem um setor de investigação, o que é ótimo, porque impede que se transforme numa burocracia. A A3ES tem como competência a acreditação prévia de todas as propostas de novos ciclos de estudos que as instituições pretendam iniciar. Esta é realizada mediante uma análise documental por uma comissão de avaliação externa. Também é competência da A3ES implementar o ciclo regular de avaliação/acreditação de todos os ciclos de estudos com acreditação preliminar. É desde a criação da A3ES que o princípio de que a responsabilidade pela qualidade do ensino cabe, antes de mais, a cada instituição de ensino superior, que deverá então criar as estruturas e os procedimentos internos apropriados para promover e garantir essa qualidade. No entanto, mais tarde, foram adotados referenciais para os sistemas de garantia da qualidade, de forma a proporcionar orientações para auxiliar as instituições. Subjacente a esses referenciais, foi também desenvolvido um modelo de auditoria dos sistemas internos de garantia da qualidade [SIGQ] com vista à sua certificação.

M.G.G.V.G. - Como analisa a questão da avaliação da educação superior em sua relação com a qualidade?

A.M. - É evidente que o ensino superior tem características simultâneas. Primeiro, é um bem de experiência; só quando o aluno começa a ter aulas é que vê onde está. Segundo, é uma compra rara, uma vez que, em regra, o aluno só se inscreve em um determinado curso. Não é como comprar batatas ou camisas, em que a compra frequente permite corrigir rapidamente uma má aquisição. Em terceiro lugar, os custos de mudança de opção são altos; mudar de curso ou de instituição é, regra geral, uma opção difícil e com custos elevados. Mesmo em Portugal, que há um concurso público para os lugares. Ora, essas características simultâneas, de ser um bem de experiência, de ser uma compra rara e ser difícil de mudar, justificam que, em conjunto, essas três características sejam uma razão para o Estado ter de proteger os alunos e as famílias, e por isso esse tipo de agência começou a surgir. Ou seja, compete ao Estado assegurar que o ensino que é oferecido nas escolas do país tenha um nível de qualidade aceitável. Essa é uma das razões pelas quais o Estado se preocupa com isso. No caso europeu, há uma razão adicional, que é o fato de o cidadão europeu poder exercer a sua profissão nos outros países europeus. Avalio positivamente a qualidade da formação em Portugal. De maneira geral, a oferta que nós temos é boa. Não há dificuldade nenhuma em jovens que terminam a sua licenciatura encontrarem emprego lá fora, na França, na Alemanha ou na Inglaterra. Por exemplo, as áreas das engenharias são muito procuradas lá fora, com enfermagem não há dificuldade nenhuma. Os nossos enfermeiros têm uma formação excelente. Portanto, como o curso de enfermagem foi acreditado por uma agência nacional reconhecida, isso significa que o curso tem o mínimo de qualidade e, portanto, é aceitável que uma pessoa possa exercer a sua profissão em outra localidade. Outra informação relevante: verifica-se, de forma evidente, que houve um aumento substancial da qualificação do pessoal docente, por exemplo, a percentagem 
de doutorados, quer no público, quer no privado, aumentou significativamente, e isso é positivo para a qualidade do ensino. Portanto, são essas as razões principais em relação à avaliação da educação superior e à qualidade.

M.G.G.V.G. - Quais são as competências da A3ES na garantia da qualidade da avaliação de cursos?

A.M. - É assim, a agência é uma fundação de caráter privado que não recebe financiamento do Estado e que subsiste à custa dos pagamentos que as instituições fazem para terem os seus cursos acreditados. Por lei, a agência tem competência para avaliar e acreditar todos os cursos e todas as instituições em Portugal. Nenhum novo curso pode entrar em funcionamento sem uma avaliação prévia, e nenhum curso pode funcionar sem estar avaliado. Depois, a agência é totalmente independente do governo. Como é que é constituída? Sendo uma fundação de caráter privado, tem um conselho de curadores, cinco pessoas, que são personalidades conhecidas pela sociedade, e esse conselho de curadores nomeia o conselho de administração por um período de quatro anos. Eu estou no terceiro período e espero não fazer mais nenhum. Mas, enquanto nomeados pelo conselho de curadores, ninguém nos pode demitir, a não ser que uma pessoa cometa um crime ou fique maluca ou morra, o que significa que ninguém pode influenciar as decisões do conselho de administração. Logo, não há recurso das decisões para o ministério e a única solução que uma instituição terá, se quiser contrariar as decisões da agência, é ir a tribunal superior. Não há nenhuma interferência do lado do ministério, ou seja, o ministério não tem nenhum representante na agência, nem as nossas decisões podem ser contestadas pelo ministro. Temos uma regra que é interessante perceber e que é o seguinte: se há um novo ciclo de estudos proposto, um novo curso, e a decisão da agência é negativa, não há nada que o possa pôr em funcionamento, nem o ministro. Se a nossa decisão for positiva em relação a um curso do setor público, o ministro não pode contestar a decisão, mas pode decidir fechar muitos cursos, porque não vai financiar. Imagine que o curso de medicina é muito caro, havia um novo curso de medicina numa entidade pública que era acreditado, porque tinha qualidade para isso, mas o ministro pode decidir que não financia, porque já há alunos de medicina que chegue e sobre. Portanto, são essas as regras, mas não pode contestar as decisões da agência.

M.G.G.V.G. - A A3ES foi criada em Portugal em 2007. Quais as razões que justificaram essa criação?

A.M. - No caso português, uma outra razão: nós tínhamos um sistema de avaliação que esteve em funcionamento entre 1996 e 2006, e acredito que tenha contribuído com a minha experiência para esse sistema. $\mathrm{Na}$ altura, quando começamos a estudar no conselho de reitores a possibilidade de um sistema de avaliação, estudamos o que então eram os três sistemas que estavam mais em vigor na Europa, que era o inglês, o francês e o holandês. Dos três sistemas, aquele que nos pareceu melhor foi o holandês, era a lei da autonomia das universidades, data de 1998. No sistema holandês, a entidade responsável pela avaliação é também uma entidade que está, de certo modo, ligada às universidades. No caso da Holanda, é uma entidade chamada VSMU, 
que significa Associação das Universidades Cooperantes Holandesas, basicamente controlada pelas próprias universidades e que fazia esse exercício. Nós achamos que esse era o melhor, porque, de certo modo, as instituições eram responsáveis pelo sistema de avaliação e, portanto, fizemos uma coisa igual. Criamos uma fundação das universidades portuguesas que estava ligada ao conselho de reitores, e essa fundação é que era responsável pela avaliação das universidades públicas. Mais tarde, veio-se a criar mais duas organizações, uma para os politécnicos e outra para os privados. $\mathrm{O}$ único problema é que esse sistema esteve em atividade dez anos e não produziu um único resultado negativo e, portanto, em 2006, o ministro pediu à ENQA [European Association for Quality Assurance in Higher Education], que é uma entidade europeia, para fazer uma avaliação do sistema, e a ENQA achou que o sistema não estava a funcionar bem. Por um lado, porque não produzia efeitos e, por outro lado, porque, de acordo com as novas regras europeias, as exigências têm de ser independentes, quer das instituições, quer do governo, e como havia uma fundação das universidades portuguesas ligada às universidades, ela não cumpria as regras europeias. Naturalmente que o relatório da ENQA foi negativo e depois fez uma série de recomendações para a criação da agência, a sua independência etc., e foi assim que a agência foi criada.

M.G.G.V.G. - Que orientações são seguidas na avaliação de cursos da educação superior e na constituição das equipes das comissões de avaliação?

A.M. - Quanto às normas de avaliação, existe uma lei, a lei n. 38/2007, e depois há um decreto-lei, o decreto-lei n. 369/2007, de 5 de novembro, que cria a agência, nos quais as regras estão definidas, além de mostrar os itens que devem ser considerados na avaliação. Além disso, a legislação portuguesa fixa também limites, por exemplo, para a qualificação do corpo docente, e, portanto, isso está tudo definido, e são essas as regras que nós seguimos. Quanto à constituição das comissões, também está determinado pela nossa legislação, o que está de acordo também com as regras europeias, de que nas comissões haverá sempre um perito estrangeiro. Ou seja, em todas as comissões de avaliação há um perito estrangeiro. Depois, também de acordo com as normas europeias, há sempre um aluno. Em cada comissão há um aluno e um perito estrangeiro, e depois há peritos nacionais que são selecionados pela agência, usualmente tendo em conta a qualidade da investigação que produzem. Habitualmente, vamos aos melhores centros de investigação, vemos quem são as pessoas e fazemos o convite.

M.G.G.V.G. - A certificação tem ajudado as universidades na prestação de serviços aos estudantes?

A.M. - Sim, é reconhecido não só no nível dos alunos, mas é reconhecido também no nível europeu. Existem no nível europeu duas entidades: uma que é a ENQA, que é uma associação das agências de acreditação europeias que obedecem às normas europeias chamadas European Standards and Guidelines [ESG], que obedecem a esses padrões. E depois existe uma coisa chamada de European Quality Assurance Register [EQAR], que é um registro europeu das agências que podem operar no nível europeu. Assim, a agência é avaliada internacionalmente de cinco em cinco 
anos. Se for avaliada positivamente, pode permanecer como membro da ENQA, e depois pode pedir a inscrição no registro europeu; estando inscrita no registro europeu, pode operar em toda a Europa, e, portanto, as nossas avaliações são aceitas em toda a Europa.

M.G.G.V.G. - Em sua opinião, a avaliação feita pela A3ES tem contribuído para a melhoria das instituições de ensino superior?

A.M. - Sim. A legislação portuguesa e também as normas europeias, digamos, que determinam que as instituições tenham um sistema interno de garantia de qualidade. As instituições devem ter internamente um sistema qualquer que garanta que aquilo que elas oferecem tem o mínimo de qualidade. E esses sistemas podem ser certificados pela agência, mas a certificação é diferente do processo de acreditação, porque o processo de acreditação é obrigatório. Nós podemos inclusivamente encerrar cursos que não sejam submetidos. Mas a certificação dos sistemas internos é voluntária, pode certificar ou não o sistema interno, não é obrigatório por lei.

M.G.G.V.G. - Existe alguma relação entre o processo seguido pela A3ES, na avaliação, e práticas internacionais na matéria? Se sim, houve alguma adaptação à realidade nacional e às instituições do ensino superior portuguesas?

A.M. - Todas as agências europeias que querem ser reconhecidas têm de seguir as normas da ESG, e as normas da ESG determinam a forma como se processa o nível de independência, o teor dos relatórios etc. Está tudo definido, e naturalmente que nós seguimos essas normas. A adaptação ao sistema nacional vem da lei portuguesa. Por exemplo, a lei portuguesa fixa as percentagens mínimas de doutorados que lecionam determinado curso, mestrado ou doutoramento. Ou seja, há depois normas adicionais que são de natureza portuguesa, mas que não contradizem as normas europeias.

M.G.G.V.G. - A avaliação de cursos de educação superior ainda convive com fatores críticos? Tem tido alguns obstáculos?

A.M. - Não, acho que correu surpreendentemente bem. É bom deixar claro que, em Portugal, há três possibilidades: os cursos são acreditados, são acreditados com condições, ou não são acreditados. O primeiro ciclo acabou e encerraram mais dois mil cursos. Mas, curiosamente, desses cursos, cerca de noventa por cento foram por decisão das próprias instituições. Outra coisa: uma grande parte do trabalho da A3ES foi discutir com as instituições a situação dos cursos. Porque são ciclos de cinco anos, os cursos foram divididos por áreas em cinco anos; no primeiro ano foi formação de professores, e o último ano, medicina. Todos os anos, à medida que era publicada a lista dos ciclos de estudo em avaliação, havia sempre uma percentagem significativa de cursos que eram encerrados pelas próprias instituições que reconheciam que aquilo não passaria numa acreditação, ou porque eram cursos que já estavam desatualizados, ou porque eram cursos que tinham poucos alunos, ou porque eram cursos que não tinham qualidade suficiente, e reconheciam isso. Grande parte das decisões foi por decisão, digamos, voluntária das instituições, 
o que mostra que de fato se conseguiu ter um efeito muito bom. Também foram encerradas algumas instituições, também houve instituições que eram universitárias e passaram a politécnicas, e também houve instituições que perderam o estatuto de universidade. Digamos, foi um processo duro, estivemos bastantes vezes em tribunal, mas nunca perdemos uma questão, principalmente, no lado do privado, houve uma certa guerra.

M.G.G.V.G. - A agência influencia a liberdade de escolha de conteúdos, metodologias de ensino? E nos processos de avaliação dos cursos, durante alguma fase do processo de avaliação e de acreditação da A3ES, foi posta em causa a autonomia científica e pedagógica das instituições ou foi considerado que tal estava a acontecer? A.M. - A legislação existente obriga a que se respeite a autonomia das instituições, e uma das recomendações que sempre fazemos aos peritos que constituem as comissões é que não podem utilizar seus exemplos da casa para forçar as outras instituições a segui-los, e os peritos nem sempre seguem isso. Se vir a lista de peritos... nós temos quase dois mil peritos, e, como foi um sistema que começou a operar há relativamente pouco tempo, também não havia peritos propriamente treinados, e, portanto, esse primeiro ciclo serviu também para fazer uma seleção dos peritos para os ciclos futuros. Houve senhores que nunca mais serão peritos, porque não se adaptavam, não eram capazes de seguir as orientações que estavam estabelecidas. Por exemplo, tentavam influenciar demasiado, e isso não é aceitável.

M.G.G.V.G. - Qual o impacto da avaliação nas funções e responsabilidade das comissões de avaliação?

A.M. - É assim, nós temos um sistema com uma característica muito interessante, que não existia no sistema anterior português, no sistema que funcionou entre 1996 e 2006: as comissões eram responsáveis pela decisão final de acreditação ou não. No novo sistema, as comissões fazem uma recomendação e a decisão final é do conselho de administração da A3ES. E isso por quê? Porque, quando o sistema anterior foi avaliado, uma das críticas que lhe foi feita foi a falta de homogeneidade das decisões, ou seja, havia comissões que eram muito brandas, comissões que eram muito duras, havia comissões que às vezes faziam um relatório e depois a recomendação não correspondia com aquilo que estava lá escrito etc. Logo, essa responsabilidade passou para o conselho de administração, e a média é de aproximadamente cinco por cento dos casos em que a decisão do conselho da A3ES não coincide com a recomendação da comissão, para pior ou melhor, isso depende, mas é assim que a agência assegura que há equidade nas decisões. $\mathrm{O}$ sistema anterior tinha esse problema, que era um problema complicado. Neste momento, temos na base de dados cerca de onze mil e tal processos, portanto temos todos os anos entre duzentas e trezentas comissões. É importante assegurar que elas tenham critérios mais ou menos equilibrados, e é por isso que houve essa alteração na legislação, a responsabilidade é do conselho de administração.

M.G.G.V.G. - Muito obrigada pela entrevista! A.M. - Espero ter contribuído! 


\section{REFERÊNCIAS}

A3ES - Agência de Avaliação e Acreditação do Ensino Superior. Conselho de Administração. Lisboa: A3ES, [2020]. Disponível em: https://www.a3es.pt/pt/o-quee-a3es/estrutura-organizacional/conselho-de-administracao. Acesso em: 22 mar. 2020. AMARAL, A. Sistemas europeus de avaliação de qualidade. Revista Portuguesa de Gestão, Braga, v. 2, p. 19-32, 1997.

AMARAL, A. Avaliação, revisão e consolidação da legislação do ensino superior. Matosinhos: CIPES-FUP, 2003.

AMARAL, A. Bolonha, o ensino superior e a competitividade econômica. In: SERRALHEIRO, J. P. O Processo de Bolonha e a formação dos educadores e professores portugueses. Porto: Profedições, 2005. p. 35-45.

AMARAL, A. A reforma do ensino superior português. In: POLÍTICAS DO ENSINO SUPERIOR: QUATRO TEMAS EM DEBATE. Lisboa. Anais [...]. Lisboa: Conselho Nacional de Educação, 2007. p. 17-37.

AMARAL, A. Alberto Amaral: "Espero que o que tiver a fechar, feche por iniciativa própria”. [Entrevista cedida ao] presidente da Agência de Acreditação e Avaliação da Educação Superior, por Barbara Wong. Portal Público, Lisboa, 22 jan. 2010. Disponível em: https://www.publico.pt/2010/01/22/portugal/noticia/alberto-amaral-espero-queo-que-tiver-a-fechar-feche-por-iniciativa-propria-1419309. Acesso em: 17 maio 2019. AMARAL, A.; FONSECA, M. Portugal: higher education and lifelong education in Portugal. In: SLOWEY, M.; SCHUETZE, H. G. Global perspectives on higher education and lifelong learners. New York: Routledge, 2012. p. 82-96. Disponível em: https://www.researchgate.net/publication/286073515_Portugal_Higher_education_ and_lifelong_education_in_Portugal. Acesso em: 22 mar. 2020.

AMARAL, A.; MAGALHÃES, A. O conceito de stakeholder e o novo paradigma do ensino superior. Revista Portuguesa de Educação, Braga, v. 13, n. 2, p. 7-28. 2000. Disponível em: http://www.redalyc.org/pdf/374/37413202.pdf. Acesso em: 23 mar. 2018.

BERTOLIN, J.; AMARAL, A.; ALMEIDA, L. Os cursos de graduação podem compensar a falta de capital cultural e background de estudantes? Educação e Pesquisa, São Paulo, v. 45, e185453, 17 jan. 2019. Disponível em: http://www.scielo.br/scielo. php?script=sci_arttext\&pid=S1517-97022019000100501\&lng=pt\&nrm=iso. Acesso em: 19 maio 2019. https://doi.org/10.1590/s1678-4634201945185453

CARDOSO, S.; ROSA, M.J.; VIDEIRA, P.; AMARAL, A. Internal quality assurance: a new culture or added bureaucracy? Assessment \& Evaluation in Higher Education, United Kingdom, v. 44, n. 2, p. 249-262, Oct. 3, 2018. Disponível em: https://www. tandfonline.com/doi/full/10.1080/02602938.2018.1494818. Acesso em: 10 maio 2019. CIPES - Centro de Investigação de Políticas do Ensino Superior. Alberto Amaral. Matosinhos: CIPES, [2020]. Disponível em: https://www.cipes.pt/?q=user/81/.Acesso em: 22 mar. 2020. 
EDULOG - Fundação Belmiro de Azevedo. Conselho consultivo. Porto: EDULOG, [2020]. Disponível em: https://www.edulog.pt/quem_somos. Acesso em: 22 mar. 2020. FONSECA, M.; JUSTINO, E.; AMARAL, A. Students' migration in a Portuguese hinterland public university. Studies in Higher Education, United Kingdom, 2018. Disponível em: https://www.tandfonline.com/doi/abs/10.1080/03075079.2018.1553 155?journalCode=cshe20. Acesso em: 12 maio 2019. https://doi.org/10.1080/03075 079.2018.1553155

PORTUGAL. Lei n. 38, de 16 de agosto de 2007. Aprova o regime jurídico da avaliação do ensino superior. Assembleia da República, Lisboa: $1^{a}$ série, n. 157, p. 5.310-5.313, 16 ago. 2007. Disponível em: https://www.a3es.pt/sites/default/files/L_38-2007_ RJAES.pdf. Acesso em: 22 jun. 2019

PORTUGAL. Ministério da Ciência, Tecnologia e Ensino Superior. Decreto-lei n. 369, de 5 de novembro de 2007. Diário da República, Lisboa: $1^{\text {a }}$ série, n. 212, p. 8.032-8.040, 5 nov. 2007. Disponível em: https://www.a3es.pt/sites/default/files/ DL_369-2007_A3ES.pdf. Acesso em: 22 jun. 2019.

TEIXEIRA,P.; AMARAL,A.; DILL, D.;JONGBLOED, B. (eds.). Markets in higher education. Amsterdam: Kluwer, 2004. [Traduzido para o chinês em 2007].

VEIGA, A.; AMARAL, A. Uma interpretação do olhar da história sobre Bolonha. Revista da FLUP, Porto, série 4, n. 1, p. 29-40, 2011. Disponível em: https://ler.letras. up.pt/uploads/ficheiros/9235.pdf. Acesso em: 18 maio 2019.

VEIGA, A.; MAGALHÃES, A.; AMARAL, A. Differentiated integration and the Bologna Process. Journal of Contemporary European Research, United Kingdom, v. 11, n. 1, p. 84-112, fev. 2015. Disponível em: https://www.jcer.net/index.php/jcer/ article/view/624/513. Acesso em: 10 mar. 2018.

VEIGA, A.; MAGALHÃES, A.; SOUSA, S.; RIBEIRO, F.; AMARAL, A. A reconfiguração da gestão universitária em Portugal. Educação, Sociedade \& Culturas, Porto, n. 41, p. 7-23, 2014. Disponível em: https://www.fpce.up.pt/ciie/sites/default/ files/ESC41_A_Veiga_et_al_.pdf. Acesso em: 12 mar. 2018.

\section{SOBRE A AUTORA}

Maria das Graças Gonçalves Vieira Guerra é doutora em educação pela Universidade Federal da Paraíba (UFPB). Professora da mesma instituição. E-mail: gracinhavieira@yahoo.com.br

Recebido em $1^{\circ}$ de agosto de 2019

Aprovado 4 de dezembro de 2019 